See discussions, stats, and author profiles for this publication at: https://www.researchgate.net/publication/333843260

\title{
Exploring the Intersection of Bisexual and Christian Identities: The Negotiation of Gendered Attraction in Intimate Lives
}

Chapter · June 2019

CITATION

1

1 author:

(2). Alex Toft

34 PUBLICATIONS 74 CITATIONS

SEE PROFILE

Some of the authors of this publication are also working on these related projects:

Bisexual Christian identity: a sociological exploration of the life stories of female and male bisexual Christians- PhD- University of NOttingham View project

My Liver App: A research project to develop a mobile application to support young people with liver conditions through the period of transition from paediatric to adult health services- Funded by CLDF (Children's Liver Disease Foundation) View project 
This is an accepted pre-print of a chapter from the forthcoming book:

Page, S.J. \& Yip, A.K.T. (forthcoming) Intersecting Religion and Sexuality: Sociological Perspectives. BRILL.

The full reference will be similar to:

Toft, A. (forthcoming). Exploring the Intersection of Bisexual and Christian Identities: The Negotiation of Gendered Attraction in Intimate Lives. In: Page, S.J. \& Yip, A.K.T. (forthcoming) Intersecting Religion and Sexuality: Sociological Perspectives. BRILL. 


\title{
Exploring the Intersection of Bisexual and Christian Identities: The Negotiation of Gendered Attraction in Intimate Lives
}

\author{
Alex Toft
}

\section{Introduction}

This chapter explores the intersection of bisexuality and Christianity specifically with regards to how this impacts upon intimate lives. The life-stories of the participants involved in the research revealed that gender was not the defining feature for relationship formation (referred to as gendered attraction throughout this chapter). The stories suggest that, for bisexual women and $\operatorname{men}^{1}$, gender is important and something to be negotiated in everyday life. However, due to the destabilising nature of bisexuality with regard to the dominant binaries of sexuality and gender, which prioritises heterosexuality and monosexuality ${ }^{2}$, it often does not play a central part in the formation of relationships. Taking this as the starting point, this chapter explores two key questions: What aspects do bisexual women and men use to form relationships when gender of the partner(s) is not the core feature? How does this influence how bisexuality is understood conceptually? Intersectionality is used as an analytic tool to understand how bisexuality and Christianity 'operate not as discreet and exclusive entities, but build upon each other to work together' (Collins and Bilge 2016: 4). This is applied specifically to intimate lives to try to understand how

\footnotetext{
${ }^{1}$ All participants were cisgendered, representing a limitation of the study. However, it should be noted that this was not a purposeful study design choice.

${ }^{2}$ Monosexuality refers to sexual identities which exclusively emphasize attraction to one sex or one gender; whereas, non-monosexual sexual identities embrace non-exclusive attraction to any sex or gender (Flanders, Robinson, Legge, and Tarasoff, 2016; Goldberg, Garcia and Manley, 2017). Bisexual-identified persons are therefore non-monosexual (see Malipaard, 2017). In relation to this, monosexism is the ideology which emphasises 'the privileging of sexual attraction to one sex or gender, from heterosexual, gay, and lesbian communities' (Roberts, Horne and Hoyt, 2015: 554).
} 
bisexual Christians are situated with regards to intimacy in relation to Christianity, monogamy and monosexism.

The chapter draws on data obtained through 80 questionnaires and 20 lifestory interviews with women and men who identified as bisexual and Christian. In the main, the data from the interviews will be the primary focus, foregrounding the life stories of the participants. I use an intersectional approach during analysis with an emphasis upon understanding the complexities of a bisexual Christian identity rather than an exploration of bisexuality and Christianity as two exclusive identities. In this regard, their sexuality and spirituality are interlinked and intersecting. This represents a shift in my understanding of their experiences and how identities are inextricablylinked. Whereas previously my work (e.g., Toft, 2009, 2012, 2014) has explored identities as formed entities which exist alongside each other and form the person's 'self', here I acknowledge that in reality referring to an individual's 'bisexual self' or 'Christian self' is reductive and restricts the representation of their experience. Identities, when viewed through the lens of intersectionality, are complex and messy, but this reflects social life. The exploration of bisexuality and Christianity needs to be undertaken in terms of a bisexual Christian identity which does not reduce individuals to compartmentalised identities; rather there is an acknowledgement that identities intersect, impact and inform each other (Jenkins, 2014; Lawler, 2013). When talking about the identity of my participants it is important to understand that this is bisexual Christian identity (not bisexual identity or Christian identity).

\section{Using Intersectionality to Explore Bisexual Christian Lives.}


The main focus of this chapter is the intersection of bisexual and Christian identities, and how this informs and impacts upon attraction and intimate lives. The stories of the participants suggest the possibility that intimate life is not dependent upon the gender of potential partners. This emerges as a result of the negotiation of aspects of bisexual and Christian identities which the participants saw as being in conflict. From the stories of the participants these negotiations appear to relate to two main aspects: How religious values inform partner(s) selection, and the negotiation of monogamy and monosexuality which are central to established Christian values. It is envisioned that an intersectional approach will also highlight how bisexual and Christian identities work together and how the participants worked to negotiate power imbalances and the social inequalities faced.

These aspects will be explored in three thematic sections which represent the participants' negotiations. First, there were a number of participants who did not feel they were rejecting or transcending gender in any way in their intimate lives. They described a negotiation of gender which was informed by their Christian identities, although they rejected monosexuality. Here Christianity was framed as being restrictive and constraining as an overbearing structural force which undermined their agency. Themes two and three, however, are what might be considered the queering of religious life, where participants enacted personal agency to disrupt traditional Christian teaching. The idea of 'loving the person' is presented as a response to how the participants' bisexual and Christian identities lead to an emphasis on attraction and intimacy based upon characteristics beyond biology. Here there will be an exploration of how the rejection of gendered attraction is a result of Christian values and bisexuality with its inherent rejection of monosexuality. Put simply, their rejection of gendered attraction is a result of their re-evaluation of the relationship 
between their bisexuality (which challenges monosexism) and their Christian faith (which upholds monosexism). The focus here is upon working outside of monosexuality and compulsory monogamy. Finally, there are participants who have been grouped in terms of 'Spiritual Connections', where I explore how Christian values have been conceptualised as not aligning with understandings of bisexuality, particularly with regards to monogamy. The participants discussed how such spiritual conceptualisations of attraction and intimacy enabled them to work within the parameters of monogamy, which is privileged in Christianity.

Throughout, I use intersectionality as a tool to explore how identities interact, the result of this and the negotiations at work. I use intersectionality as a means of exploration and critical thinking which sheds light upon the complexity of lived experiences. Intersectionality has been framed as 'vague' (Davis, 2008: 69), although it is worth noting that this is not meant as a critique, rather an acceptance that the lines of analysis are potentially endless; and definitions and applications have been diverse. Compare, for example, Munro and Richardson (2010) and their intricate application of intracategorical complexity to the LGBT acronym with Gutmann Khan and Lindstrom (2015) who use an intersectional framework to explore privilege and oppression in relation to possessing multiple fluid and socially constructed identities. This perhaps highlights the lack of consistency around the use of intersectionality, and a lack of established definition; but it also shows flexibility and the way it can be moulded to fit specific purposes. Underlying all such analyses is an attempt to understand human experience as shaped by multiple factors that work in a diverse manner (Collins and Bilge, 2016). However, Collins and Bilge argue that such variation has led to theorisation which is potentially misaligned to the overall goal of intersectionality, or at least not fully accessing the potential which intersectionality 
has to uncover complex life experiences. This is particularly pertinent in relation to a school of thought within identity politics that could be labelled as 'intersectionalitylite', where intersectionality is used as an additive identity theory to explore the experiences of individuals who possess multiple and potentially conflicting identities. Of course, such exploration is important, but this shifts intersectionality towards a theory of identity to investigate how multiple identities are combined to create unique individuals, rather than an exploration of power and inequality; therefore, simplifying intersectionality and potentially undermining its potential. Collins and Bilge suggest that this viewing of intersectionality as a theory of identity in this manner may not result in the fulfilment of intersectionality's potential to be used as an analytical tool to examine 'how power relations are intertwined and mutually constructing' (2016: 7).

With this tension in mind my goal is to ensure that my analysis addresses issues of power imbalance and social inequality, whilst being open to understanding how the collision of identities impacts upon the life of the participants. The aim and use of intersectionality within this chapter is also slightly different to other applications with its focus upon intimate life. The areas of power imbalance and social inequality revolve around religious life (Christianity) and how bisexuals negotiate monosexism and non-compulsory monogamy in relation to their intimate lives. Ultimately, intersectionality is used as an analytical tool to understand how bisexual Christians' intimate lives are situated in relation to structures which potentially create power imbalances, particularly in relation to the Christian Churches teaching on sexuality; and how inequality is perpetuated through normalised visions of intimacy and attraction to which bisexuals may not fit. 


\section{Understanding Bisexuality and Christianity}

In order to explore whether the participants rejected gendered attraction and prioritise other attributes, the chapter will first explore how this fits with bisexual and Christian discourse. I have previously argued (Toft, 2014) that my participants felt more committed to their bisexual identities, with some describing it as their core identity. As a result it is important to consider bisexuality in some detail in this regard. The participants often framed Christianity as more fluid and malleable; however it is important to briefly explore what previous literature has said about bisexuality and Christian teaching.

The review will then do two things: First, explore the literature on bisexuality which has suggested the revolutionary or transcendent nature of bisexuality with regards to gendered attraction and intimacy. Second, the review will present the literature on how Christianity understands bisexuality, with a specific focus upon traditional teaching on intimacy and relationships.

\section{Bisexuality}

Research on bisexual experience has slowly grown, and yet a number of unresolved debates still surround it as a concept. Perhaps most striking are theories which attempt to downplay gender as central to bisexual experience. With such ideas, according to Pennington, 'authors propose that bisexuality erupts dichotomous categories of identification and opens up new possibilities through fluidity of experience' (2009: 39). This is due to an assertion that bisexuality potentially disrupts binaries (sex/gender, male/female) as bisexuals do not fit on this schema; potentially 
revolutionising sexual identity (Firestein, 1996; Hall, 1996). Jeffreys asserts that 'bisexuality is so diverse and fluid in its practice that it can be seen to present the ideal postmodern practice' (1999: 279).

In this respect it is difficult not to make links between bisexuality and postmodernist theorisation of gender, particularly the work of Butler. Whether bisexuality is a representation of such ideas or not, bisexual experience appears to aid in the confirmation of gender as a performance which is formed through the repetition of male or female acts:

Gender is the repeated stylisation of the body, a set of repeated acts within a highly rigid regulatory frame that congeal over time to produce the appearance of substance, a natural sort of being. (Butler, 1990: 33)

As a result, gender is conceptualised as plural rather than binary. Munro, whilst exploring the impact of such pluralisation on LGBT studies, noted:

...gender pluralization has profound effects on the ontological foundations of sexual orientation. It means that male, female, and the lesbian/gay/heterosexual (LGH) categorizations that are built on these identities are not discrete, and a range of other sexualities become apparent. (2018: 1)

It could be suggested, therefore, that bisexuality adds to the problematization of gender and, as Munro notes, the demarcation of certain identities and their ascription to specific genders. Such a standpoint, however, has been used historically to present bisexuality as revolutionary or utopian in its relationship towards sex and gender. Scholars have, arguably, used Butler's messages for their own agendas without 
engaging with actual bisexual people. For example, Marjorie Garber controversially assigned bisexuality as an anti-identity beyond any sort of categorisation: 'It is an identity that is not an identity, a sign of the certainty of ambiguity, the stability of instability, a category that defines and defeats categorization' (2000: 70).

Such a standpoint is appealing, as it represents bisexuality as potentially revolutionary in nature, where sexual identity takes its cue from bisexuality moving away from categories of sex and gender, and as a result, neatly bypassing associated power struggles, as summarised by Angelides:

...bisexuality as a definite human species would disrupt the very classificatory alliance of sex/gender and sexuality. It threatened to absorb both of these differentiating human registers and dissolve the boundaries of human identity. (2000: 47)

Additionally, both Highleyman (1995) and Daumer (1992) suggest that as categories of 'sex' and 'gender' lead to exclusion and phobia, bisexuality, it is argued, has the potential to move beyond this.

Such ideas have been met with concern from a range of scholars and activists, particularly those working in the fields of bisexuality and lesbian feminism. Wilkinson (1996) suggests that such radical new bisexuality represents bisexuality as nothing more than a fashionable trend, an understanding in which anyone can be bisexual, emphasising the way engaging with bisexuality has become a fun pastime or slice of entertainment. Bisexuality as an identity in this scenario has been dissolved into bisexuality as an activity which continues to reap the rewards of heterosexual privilege (Stone, 1996). Lesbian feminists such as Stone (1996) and Jeffreys (1999) have shown how such an approach to gender and sexuality undermines feminist 
achievements and, according to Stone (1996), a reliance on men when the going gets rough.

A number of scholars categorically reject such implications. Eadie, for example, argues that it is important to not lose sight of the fact that bisexuality is concerned with attraction and what sexual feelings mean, stating that bisexuality is 'simply one way amongst many of learning what is and what is not erotic, what such feelings mean, and the culturally sanctioned forms in which they may be expressed' (1997: 8). Storr (1999) has also been clear upon this point, warning against the hyperbolic nature of some theory which frames bisexuality as revolutionary and without boundaries.

Although at its core bisexuality is about sexual attraction, behaviour and identity (Robinson, 2015), it is often difficult to 'display' bisexuality, particularly in scenarios which do not lend themselves to what is popularly understood as bisexual (e.g. monogamous relationships) (Hartman-Linck, 2014). 'Displaying' bisexuality in this regard originates from the question Hartman-Linck proposes; how is bisexuality maintained and made visible in monogamous relationships? Hartman ${ }^{3}$ (2013) suggests that displaying in this regard relates to the attempt to project a bisexual sexual identity and to make it visible for others. Such cues or acts may relate to private displays such as the study of bisexuality, desire and fantasy, creating bisexual/queer spaces. The example of an apartment with queer things in, such as books, is suggested (HartmanLinck, 2014).

This is where confusion between 'revolutionary' bisexuality and 'display' occurs. 'Revolutionary' refers to a transcendence of gendered life, whereas 'bisexual

\footnotetext{
${ }^{3}$ Hartman-Linck and Hartman are the same author.
} 
displays' clearly downplay the importance of gender as a force for attraction. As Hartman-Linck (2014) argues, in working to accentuate the bisexual display other aspects of character and identity have the potential to become more central. This does not mean that any transcendence is taking place; it is simply other aspects become more important or relevant. As she states in relation to her work with monogamous bisexual women:

Bisexuality does not go away because of the commitments one makes to another person, and learning more about being bisexual outside of sexual behavior has great potential in forging political alliances that can move beyond mere identity politics. The women in my sample wanted to be visible and recognized as bisexual women even though they were not using this visibility as a means for attracting sexual partners. (Hartman-Linck, 2014: 190-191)

Hartman-Linck has begun to explore how political motivations and alliances are important parts of bisexual identity: 'By understanding bisexuality outside of just sexual behaviour we can examine the ways nonsexual motivations, such as political beliefs and ideology, shape sexuality, and vice versa (2014: 191).

I align myself with this perspective and argue that this is not suggesting that bisexuality revolutionises our understanding of sex and gender and dualistic categorisation; rather there is a realisation that there are other aspects that become important beyond gender. In Hartman-Linck's work visual displays are the main focus, in response to the assertion that bisexual identities are erased and it is often important to visualise and/or accentuate identities to ensure authenticity. I will suggest 
that there are also internal negotiations which take place due in main to the intersection of bisexual and Christian identities.

\section{Christianity}

Official standpoints on bisexuality are often not readily available, due mainly to the apparent rejection of lifestyles which vary from cross-sex marital relationships. As Shepherd states:

There is no liturgical framework, no theology, no Christian ethic on how to live holistically as a bisexual or bi-intimate follower of Jesus Christ, whether sexually active or not. (2018: 3 )

However, the Anglican Church through its House of Bishops' publications does address bisexuality and lays out aspects of teaching which are relevant here. It is important to note that the bisexuality that is presented and the way that the Church envisions bisexuality being enacted, bears little resemblance to the lives of those taking part in my research. The Church presents bisexuality as a choice (e.g. it is possible to choose to be in cross-sex relationships if you are bisexual and ignore all same-sex attraction) (House of Bishops, 2003: 283). Bisexuality is also framed as being multi-partnered and promiscuous by design (House of Bishops, 2003: 282). The root concern for the Anglican Church revolves around monogamy, same-sex relationships, and marriage. The document clearly suggests that the ideal position is to be in a committed married monogamous relationship with one member of the opposite sex. The only possible alternative to this is abstinence (House of Bishops, 2003: 283). 
Other Evangelical or conservative Christian denominations have failed to move beyond a consideration of gay relationships. Bisexuality has not been significantly addressed, although the research in this area (see Thumma, 1991) has called for a re-evaluation of literal interpretations of the Bible, on which such conservative denominations heavily rely.

Liberal denominations, represented in my sample by those attending Metropolitan Community Churches (MCC), are more open to the possibility of bisexual and queer youth. Research with MCC members (Wilcox, 2003; Cuthbert and Taylor, 2018) suggests that this is as a result of more active interpretation of religious doctrine, which may be potentially welcoming towards bisexual Christians.

It is important to note that such teaching usually offered little more than a guide for the participants in my research, as their stories highlight religion as a lived experience (Hall, 1997; McGuire, 2008; Orsi, 1997). Yet, it is important to understand the teaching they are working with and what they have to negotiate. In reality, teaching and guidance often comes from religious leaders, and to focus solely upon official standpoints would be missing key points of contact for congregations. Research exploring the views of pastors and educators in the UK and USA found that because binary thinking was so sharply ingrained 'acceptance of the bisexual orientation in churches and wider society remained a distant dream' (Shepherd, 2018a: n.p.). However, the research suggests that the picture is complex, with a polarisation of views across denominations. For example, monogamy was strongly upheld in denominations where the Bible was taught more literally, whereas more liberal denominations (Shepherd highlights Quaker, United Church of Christ, and Unitarian Universalist churches) were more open to polyamorous life within the 
Church. Shepherd concludes that overall, Christianity is unwilling to entertain the complexity of bisexual identities as doing so would disrupt existing bases of power.

\section{Methodological Account}

This chapter uses data collected from a UK project which collected 80 interviews and 20 in-depth life story interviews. The wider project from which this chapter takes its data explored how bisexual Christians negotiated their identities, with a focus upon the strategies the participants employed, in order to live fulfilling lives ${ }^{4}$.

The questionnaires served as guides for the interview schedules and collected information on: demographics, relationships, sexuality, religious faith and practice, support networks; and life as a bisexual Christian. Twenty interviewees were then invited to take part in detailed semi-structured interviews using individually tailored schedules. Although reported elsewhere (Toft and Yip, 2018) it is important to present an overview of the sample for clarity: The entire sample (80 participants) consisted of $42(52.5 \%)$ women and $38(47.5 \%)$ men, with ages ranging of 18 to 72 (with a mean age of 28 years). Most of the participants (78; 97.5\%) self-defined as 'white British'. In terms of relationship status 17 participants $(21.8 \%)$ were single; and $52(66.7 \%)$ were in coupled relationships (33 cross-sex and 19 same-sex). The sample were not exclusively monogamous, with nine participants (11.5\%) who were in relationships with at least three partners, comprising a mixture of cross-sex or same-sex partners

\footnotetext{
${ }^{4}$ The empirical data upon which this chapter draws was funded by the Economic and Social Research Council (Award No: PTA030-2006-00245).
} 
(two participants did not respond to this question). Relationship duration ranged from one month to 32 years.

\section{Gendered Attraction in Bisexual Christians' Intimate Lives}

Yip and I have shown that personal understandings of bisexuality often centre around other characteristics than a person's gender. Indeed, we noted that the life-stories of the participants place:

...emphasis on gender-transcending characteristics - reflecting the popular trope 'it is the person that counts' - fundamentally challenges the discursivelyproduced association between sexual attraction and gendered body, which hegemonizes heterosexuality - and is increasingly accepting of homosexuality - but continues to invisibilize and marginalize bisexuality. (Toft and Yip, 2018: 238)

Here I will explore this in greater detail in relation to the participants as bisexual Christians and the impact of this intersection. The data reveals three broad themes in this regard. First, 'negotiating gender', exploring the participants who in contrast did not feel that they were in anyway transcending gender and worked to negotiate it in their lives, framing Christianity as a constraining and reductive force in their lives. Second, 'loving the person', shifting emphasis away from gendered attraction towards other aspects and personality characteristics, in line with Christian values and beliefs. Finally, 'spiritual connections' which emphasises the role of spiritual compatibility and common interests, often working within monogamous frameworks. 


\section{Negotiating Gender}

This theme highlights the challenging negotiations that the participants had to work through, where faith was seen as restrictive. As suggested in the literature review, although radical bisexual scholars and activists have conceptualised bisexuality as a revolutionary movement which erases gender roles and boundaries, this is problematic on a number of levels. As a result, it is logical that gender would still be a source of negotiation for some participants, especially due to their considerations of Christian teaching. It is important to note that participants in a number of instances had adopted monogamy as the only viable option, reflecting their commitment to their interpretation of Christianity and the teaching of their Church. This was most clearly represented in how the participants negotiated monogamy and gender roles in their intimate lives.

Delilah was a 21-year old woman from the North-West of England who was a practising Christian, having been brought up in a strongly Roman Catholic family. Throughout her life Delilah had engaged solely in monogamous relationships. Delilah explored how upon relationship formation she would be attracted to certain things in relation to the gendered body and traits that she labelled as male or female:

It's so difficult, because if I'm in a relationship with a girl I generally miss all the things, you know, guy things. But if I'm with a guy I miss the girl things. It's all very...it's just different ways of relating to each other. But then maybe I just date stereotypical guys and girls... I think if I met the right person it wouldn't matter, and that's the main thing, if you meet the right person it doesn't matter if they are a guy or a girl, I can be attracted to both. And I need to be honest for my own peace of mind. 
Delilah emphasises her need to be clear and honest; with her male partners she is attracted to what are seen as traditionally masculine traits and she is attracted to stereotypically feminine traits in female partners. This rather rigid description of her attraction suggests that Delilah feels that relating or engaging with partners is different dependent upon their 'sex'; and that ultimately, she is only attracted to a certain type of person. She describes a negotiation of how she forms partnerships and how she interacts with other people, and it is clear from Delilah's life-story that within certain relationships, she misses certain aspects of maleness/femaleness. Although Delilah cannot imagine meeting a person who would fulfil all elements of her desire, given how she constructs masculinity/femininity to a sexed body, she continues to practise monogamous relationships with the hope that she will meet someone with whom she forms such a bond that this no longer matters. It appears a logical assertion that for Delilah her mode of attraction and how she relates to people might be better fulfilled in polyamorous relationships. However, polyamory is not an option for Delilah as she felt that it would conflict too sharply with her religious beliefs. Delilah's life experiences do not reflect a challenge to binary categorisation. This suggests that although bisexuality offers the potential to challenge such categorisation; as clearly shown in the literature review of this chapter, it is not a preprerequisite of bisexuality.

Other participants felt this tension also. Samantha was a 19-year old woman from the North-West who had recently ended a relationship with a man. She described her attraction to what could be seen as conventional gender norms in terms of appearance and initial attraction.

With men you want the masculine things; it is this masculinity that is attractive... wider strong shoulders and a hard body. Yet for a female partner 
you want the feminine things, and I'm talking about stereotypical things here but I want a woman that looks like everything I think a woman should look like. Soft skin, curves and the like.

Here Samantha is quite openly talking about her preferences with regards to what she finds attractive. She accepts that such things may be seen as stereotypical but does not see this as problematic. Later in the interview Samantha suggested that she was simply being 'honest' about her attraction and that she felt that 'in terms of when I see someone I make a snap judgement about them, whether they are good-looking beautiful or whatever. I do this on what I think is good-looking or beautiful'. Samantha also practised monogamous relationships and similarly to Delilah there was a suggestion that she was still trying to negotiate how this attraction would manifest in her intimate life as she journeyed through life. How this intersects with their Christian identities was briefly noted by both Samantha and Jim. Samantha noted physicality and pondered whether she had been influenced by her Christian upbringing. During the interview she asked: 'I wonder why? Must be what I picked up from Bible studies I guess, like at Sunday school'. There is the suggestion that she has internalised conservative Christian teaching about relationships and how ideal forms of relationship should look. However, such forms are normalised and reinforced throughout society. Society is based around such relationships and as Rich (1980) powerfully articulated, they are proliferated to the point of becoming compulsory.

Jim was a 21-year-old man who was currently in a relationship with someone identifying with the opposite gender. He discussed how for him, monogamous life fits with his religious beliefs but also did not feel inauthentic or incomplete in anyway: 
Yeah there were certain things about either sex that I'd find attractive by looking at people, and they were specifically aimed at a certain sex. So this developed towards the end of my High school time, but I guess that's why I'm monogamous, I don't need to have both sexes because I get enough from whoever I am with...that perhaps sounds a bit selfish doesn't it, I don't mean it like that...(long pause) I guess I mean I'm just happy with who I am with at the moment, I don't pine for a person, you know...of the different sex from what I am with at the time. There are other things that are attractive about a person rather than genitalia.

Such expressions of desire may appear heteronormative. Yet such an assertion clearly denies the validity of bisexual identity for monogamous individuals. To return to the work of Hartman-Link, choosing a monogamous relationship means that individuals are then 'defined based on whom they chose as a partner, creating even more invisibility for this marginalised group (2014:177).

Such a reliance upon gender norms is not exclusive to those who identified as monogamous. Daniel was a retired man from the South-West of England who, after the passing of his wife, had become part of a group of six male partners who interacted and socialised; having sex in a variety of arrangements. Daniel was clear that the men he was attracted to must resemble what he understood to be masculine, and women should what he thought of a stereotypically feminine.

This illuminates Daniel's desire for intimacy based upon maleness or masculinity. Once this is established for Daniel it is clear that he is rather rigid in terms of openness towards sex and gender. It is important to note of course that although he identified as bisexual, Daniel was only seeking intimacy with men and 
had no plans to pursue relationships with women. Although several of the men in his group were married, their female partners did not engage in the group dynamic. This has much to say about the intersection between bisexuality and Christianity, particularly with regards to the influence of traditional understandings of Christianity. Although the participants highlight several ways that intimate lives are enacted, through multiple partners, through sequential relationships or through a constant negotiation to get a balance between masculinity and femininity, the stories all reflect what could be considered traditional gender roles in sex and relationships. This is the ingrained binary thinking highlighted by Shepherd (2018a) which is reflected in the teaching of pastors and educators throughout the UK and USA. It is likely that this way of thinking has been learnt and internalised by the participants who practised this in their intimate lives.

The negotiation of gender in this manner, from an intersectional perspective, highlights the dominance of monogamy as a societal norm and the perceived reenforcement of this through Christian teaching. The Churches' messages work to 'other' any deviance from this model and frame bisexuality as inherently unChristian. Intersectionality sheds light on how bisexual Christians are potentially situated outside of gendered and sexualised understandings of Christianity and denied access to such religious space. As a result, this group of participants garnered a collective identity which downplayed monosexuality and non-monogamy.

\section{Loving the Person}

It has become part of popular parlance to say that one falls in love with the person, rather than being attracted primarily based upon how someone looks. Popular 
psychology, for example, stresses that there are a number of factors that work alongside physicality or in fact are of greater importance. Such theories have suggested for example, that logic is seen as the most important (whether lives are compatible), followed by emotion (trust, uniqueness etc.), status (confidence, beliefs) which is at the bottom of the pyramid with health (physical attraction) (see Kim, 2015). However, the intimate lives of bisexuals appear to be a different consideration, as the intimacy is not dependent upon the gender of the individual, which is taken as a precursor in such theorisation. This could potentially be more complex in terms of initial attractions based upon appearance, as gender in this regard is not the first consideration to potential relationships. Loving the person or falling for the person then, in this respect, refers to the formation of intimate relationships based upon other aspects of an individual's character. It could be suggested that due to the fact that bisexuals are not monosexual, other characteristics become more central and take on more credence in potential intimacy.

A number of participants specifically discussed how there were other aspects which replace gender as an initiator for relationships and intimacy. These participants indicated that there were specific character traits or attributes that they regard highly and desire partners to possess. 'Loving the person' is displayed by placing greater emphasis on personal traits or characteristics over gender. This was explicitly articulated in one of the questionnaire responses from Florence, a 21-year old from the Midlands of England who suggested that she focussed on three main things, namely 'sense of humour, political ideology and attitudes to current affairs'. She pointed out that 'genitals don't matter, I want their mind. I want to know they are good and support my view of the world, they are suitably left-wing and they can make 
us both laugh!' Here Florence is highlighting a key issue for many of the participants, because gender is less of an issue, other aspects are prioritised.

In addition to describing this as 'loving the person', participants referred to openness and being receptive to people without gender being delineating boundaries. Elanor was a 24-year old from London; she was in what she considered as a long-term (4-year) relationship with someone who identified with the opposite gender. It was envisioned that they would move in together and cohabit soon. Elanor expressed this openness thusly:

It's...just fall[ing] for the person... it's the only way I can describe it to you. It's about being open to people and getting to know people on a greater level...

Here the emphasis is being placed upon openness and a deep and close relationship with an individual(s). Knowing people on a greater level is suggesting that with less focus upon sex and gender there is an emphasis on knowing the partners' thoughts and feelings in a much more in-depth manner in their intimate lives. Elanor continued to explore this during the interview and discussed how, for her, attraction is not an instant physical event; it takes time to become attracted to someone through interaction and getting to know them. She explained:

As I said, I think I don't get people until I know them and then I am attracted to them - who they are how we relate. If we hit it off and if something happens out of it, it is because I am attracted to them as people.

Throughout her description of her life experiences Elanor eludes to attraction to the 'person', inferring that this is the most important aspect of relationship formation and her intimate life. However, she was not expressly clear about what this meant in 
practical terms. In talking about 'the person', Elanor appears to be referring to character traits and personality, focussing upon what makes them the person(s) they are. For Elanor it appears that defining these traits or characteristics is futile as she is focussed upon getting to know the person as a whole, rather than being attracted to specific attributes.

The important question to consider is whether this emphasis on attributes beyond physicality is unique to bisexuals or indeed bisexual Christians. I propose that it is a heightened factor in the intimate lives of bisexuals because, as noted, their intimate lives are not defined by monosexuality. However, the stories of the participants suggest that the intersection of their Christian identity also accentuates this aspect of their lives. Due to their Christian values, the participants explored being more open and loving. This was most striking in relation to discussion surrounding Jesus Christ. Rose was a 29-year old woman from the North-West of England who had been in a relationship with a man for about a year. She took inspiration from the actions of Jesus and her interpretation of his character:

I do want to follow the example of Jesus because that is the ideal way to be isn't it. That's the point of the New Testament...that's what I want for my relationships. [I] want my life to be open to the idea of being attracted to everyone and having the potential to be with anyone... of course if I click with that person.

Once again openness is mentioned in relation to being open towards people and receptive to diverse relationships. Rose characterises Jesus as someone who is involved in improving society through love and acceptance and as having a strong sense of social justice. The messages of inclusion within the New Testament are also 
referenced. Rose stated that for her, 'Jesus represents a kindness and thoughtfulness that I want in my life, I don't think you can do this without being open to all people and being willing to embrace all people; everything else excludes people'. This is a telling quotation and represents a desire to 'love the person' guided by Christian values. Rose makes an explicit link between her religious faith and sexuality, which not only represents actively engaging with religion (rather than passively accepting) and working to fit religion with one's life (Woodhead, 2001), but also highlights how the identities of Christianity and bisexuality intersect and inform each other.

The linking of Christian values, guided by the teaching of Jesus, was common throughout the stories of the participants. As they worked to negotiate the perceived contradictions between Christian and bisexual life, they re-evaluated Christianity as a form of lived religion in line with Woodhead's assertion that Christianity is becoming a more active and agency-driven project. This was reflected in a number of participants' attitudes to intimate life who, like Rose, stressed the importance openness and what was framed as by Jim as the 'Christian way':

I try to think about doing the right thing and living in the Christian way. In my relationships and when I meet people too, being receptive and engaging with person as fully as I can.

\section{Spiritual Connections}

This section explores an emerging theme which is specifically linked to the intersection of the participants' bisexual and Christian identities and how this informs their intimate lives. Namely, how the participants explored the role of a spiritual 
connection and its importance above the sex or gender of their partner(s). For some participants, it is religious belief or identity which is the guiding force in their intimate lives, resulting in their religious identity informing their management of other aspects of their selves, including sexual identity. In many ways this is similar to what has recently been described as demisexuality (see Lord, 2016), which refers to the need for a strong emotional bond before sexual attraction occurs. The stories of the participants here suggest that this emotional bond is primarily established through a spiritual connection.

Cynthia was a 43-year old woman from the South-West of England. She had been in a same-sex relationship for just over a year and was in the process of planning a civil partnership. For Cynthia, the sex and gender of a person takes a back seat in relation to who they are spiritually. She aimed to connect with someone on a deep spiritual level. In order to create such a bond, she felt that her religious beliefs have to connect with her partner's beliefs:

But as I say it's not about the sex of the person, just the person themselves and whether I connect with them and for me the connection is spiritual. If we connect spiritually that is most important.

Cynthia attempted to explain this more fully using the example of her intimate life. She suggested that the act of love-making itself is a religious event and goes deeper than the sex and gender her partner:

For me, when I make love with my partner, it is not the physical act of genital sex; I could be holding my partner's hand and worshipping God and doing that in a way that inclusively links my spirituality with my sexuality. We are 
making love together; we are making love with God. Love is not just a sexual act.

Here Cynthia is aligning her sexual and religious selves very clearly; they intertwine and inform each other around a central pillar that is God. Such a form of attraction can be difficult to grasp for non-religious people and yet for Cynthia, this underlines her partnership and her intimate life. Another participant, Serena, a 45-year old woman who regularly attended a Russian Orthodox Church, explained that although she was 'reasonably certain that if I was starting my life all over again, I would choose to be with another woman, and probably still define as bi but not be in a primary relationship with a man', she had been attracted to her husband because of a shared religious belief and synthesising of Christianity. This had led them to develop such a strong spiritual bond that she felt life apart would not be fulfilling. Although this quotation may seem negative, as it suggests that Serena had lived a life she regretted, Serena stated that the spiritual bond was built upon 'love and togetherness and a spirituality which we share and keeps our relationship strong'. Participants suggested that such spiritual bonds were accentuated due to their bisexual identities as sex and gender was not the first stage for intimacy.

Not all participants were as positive about the intersections between their sexual and religious identities, and this has often resulted in compartmentalisation which erects boundaries around certain life-paths or beliefs. Such potential compromises and conflicts represent areas of negotiation and challenge for participants. Michael was a 27-year man from the East Midlands of England who was currently in a same-sex relationship and had been for approximately one year. Michael was somewhat conflicted about his monogamous relationship. Although he 
found he had a strong spiritual connection with this partner, he was keen to explore the difficulty he would have faced if he was not in a monogamous relationship:

Would I be any different if I was an atheist bisexual? Well I would say, 'Yes' because there wouldn't be as many things that I would have to consider like the Church's moralistic approach to open-relationships...I'm monogamous and I feel lucky because that fits in with Christian understandings, but if I wasn't it would be difficult and I think I would just have to force myself to be monogamous.

Although bisexuals can be in monogamous relationships, monogamy is not a prerequisite or assumed social norm in their lives, as noted by Anderlini-D'Onofrio (2004). As Klesse (2016) has argued, bisexuals are often seen as being fundamentally non-monogamous and that this is essential to being bisexual. Therefore, it is perhaps understandable that Michael feels such a conflict. It could also be argued that this is accentuated due to the pressures of what Michael perceives as being Christian morality and teaching with regards to how people should live their intimate lives. Michael's struggles and negotiations were noted later in the interview when exploring how he viewed his future intimate life. He suggested that he would 'like to be in a more open relationship with other people' and that he thought 'this will be more fulfilling and be more who I am'. It is clear that although he has what he referred to a 'spiritual bond' with his partner, he struggled to express his sexuality in an authentic manner due to what he saw as clear Christian doctrine of monogamy.

Thinking about this approach from an intersectional standpoint, the refocussing upon spiritual connections suggests a forming of the collective identity of bisexual Christian in order to engage with the dominant power imbalances, 
specifically the Christian Churches perceived framing of monogamy and monosexuality. The participants explore a collective identity which challenges understandings of sexuality and intimacy that is potentially at odds with bisexual lives.

\section{Concluding Remarks}

Throughout this chapter I have shown how bisexuality as a concept has been debated and that a number of such debates revolve around the weakening or downplaying of gender binaries in intimate life. As highlighted, some scholarly literature has claimed that bisexuality has the potential to revolutionise gender identity politics by breaking down the binary approach and rejecting dualistic understandings of sexuality. However, this does not necessarily correspond with how bisexuals live out their intimate lives, and as the data in this chapter indicates, this may even be an ill-judged goal. However, within the study of sexuality, bisexuality remains uniquely placed and the study of bisexual erasure and the invisibility of bisexual identities does much to challenge monosexism and compulsory heterosexuality within wider society. As a result of this monosexist binary approach which is consistently hegemonised, bisexual identity does represent less reliance upon 'gender' and 'sex' in intimate lives, particularly in terms of attraction. This does not suggest that bisexuality is simply a postmodern expression of sexual identity $($ Hall, 1996) or that it will revolutionise sexual and gender politics, but it does suggest that due to these established norms in society, bisexual relationships and intimate lives can be initiated and maintained differently. This is in line with, and builds up on, previous findings (Toft and Yip, 
2018) which assert that bisexual experience is disruptive to sexual and gender orders and that it serves as a useful way to critique monosexism in society.

The intersection between bisexual and Christian identities creates a rather unique situation as non-monosexuality, non-compulsory monogamy and Christian values and teachings collide and enmesh. As a result, it has been suggested that for the participants gender plays a less central role in intimate lives.

This chapter has shone particular light on the intersection of bisexual and Christian identities as participants worked to negotiate their sexual lives within the context of their religious belief. The participants suggested that 'loving the person' was important, focussing upon the person as a whole, or other characteristics that were found to be attractive. The participants also explored the role of a spiritual connection as a point of attraction and a force in keeping relationships strong. Such negotiations showed a diversity of beliefs and diversity in the ways religion was enacted in the participants' lives. For some Christianity was viewed as restrictive and not fully compatible with their intimate lives, yet for others it a chance to express their love freely, forming a relationship with the divine.

In this regard the sections 'Loving the Person' and 'Spiritual Connections' have focused upon an intracategorical approach to an intersectional analysis according to McCall (2005), where the focus begins upon a group of people but moves to explore categories and identities raised by the participants in order to explore 'the impact of interconnected social identity axes within the same social group (Corus and Saatcioglu, 2015: 418). The focus of such an approach is to study the intersections in an in-depth manner (Bagilhole, 2010) whilst focusing upon diversity of lived experiences across a range of identities which face a multitude of oppressions 
(Mattsson, 2014). As Walby et al. (2012) highlight, for McCall, the intracategorical approach attempts to 'focus on particular social groups at neglected points of intersection' 'in order to reveal the complexity of lived experience within such groups' (McCall, 2005: 1773-1774). Following the lead of Cronin and King (2010) the analysis started with a defined group, 'bisexual Christians', and then focussed upon how religion interacts with sexuality and gender. The result of which, in relation to attraction and relationships, has been a downplaying of gender and a focus upon other personal characteristics. The ability of bisexuality to disrupt gender norms is key here, especially when combined with the pluralisation of gender. In practice, the life stories of the participants highlight a 'queering', where the key tenets of queer theory exist in their sexual and gendered lives, and also their religious lives. Using Lanser's (2018) three definitions of what queering means, it is clear that much of what has been discussed in this chapter is present:

(1) to make a claim for the non-heteronormative sex, gender, or sexuality of someone or something; (2) to disrupt or deconstruct binary categories of sex, gender, and/or sexuality; and (3) to disrupt or deconstruct any entity by rejecting its categories, binaries, or norms. (2018: 924)

This is also present specifically in relation to their religious lives and engagement with Christianity. This resonates with Yip's use of queering in relation to religious texts where texts are de-stabilised through 'transgression and de-construction of naturalized and normalized hermeneutics, which reinforces heteronormativity' (2005: 51). The queering of religion via bisexuality is evident through the life-stories of my participants who de-stabilise sexuality, gender and religious identities. 


\section{References}

Anderlini-D'Onofrio, S. (2004). Plural Loves: Designs for Bi and Poly Living. New York: Haworth Press.

Angelides, S. (2001). A History of Bisexuality. Chicago: The University of Chicago Press.

Bagilhole, B. (2010). Applying the lens of intersectionality to UK equal opportunities and diversity policies. Canadian Journal of Administrative Sciences/Revue Canadienne des Sciences de l'Administration, 27(3): 263-271.

Butler, J. (1990). Gender Trouble: Feminism and the Subversion of Identity. London: Routledge.

Collins, P. H. and Bilge, S. (2016). Intersectionality. Cambridge: Polity Press.

Corus, C., \& Saatcioglu, B. (2015). An intersectionality framework for transformative services research. The Service Industries Journal, 35(7-8): 415-429.

Cronin, A. and King, A. (2010). Power, inequality and identification: Exploring diversity and intersectionality amongst older LGB adults. Sociology, 44(5): 876-892.

Cuthbert, K. and Taylor, Y. (2018). Queer Liveability: Inclusive Church-scenes. Sexualities. [Online First] Available at: https://doi.org/10.1177/1363460718772759 [Accessed 2 February 2019].

Davis, K. (2008). Intersectionality as buzzword: A sociology of science perspective on what makes a feminist theory successful. Feminist Theory, 9(1): 67-85.

Daumer, E. D. (1992). Queer ethics; or, the challenge of bisexuality to lesbian ethics. Hypathia, 7(4): 91-105. 
Eadie, J. (1997). Living in the past: Savage nights, bisexual times. Journal of Gay, Lesbian and Bisexual Identity, 2(1): 7-26.

Firestein, B.A. (1996). Bisexuality: The Psychology and the Politics of an Invisible Minority. London: Sage.

Flanders, C.E., Robinson, M., Legge, M.M. and Tarasoff, L.A. (2016). Negative identity experiences of bisexual and other non-monosexual people: A qualitative report. Journal of Gay \& Lesbian Mental Health, 20(2): 52-172.

Garber, M.B. (2000). Bisexuality and the Eroticism of Everyday Life. New York: Routledge.

Goffman, E. (1971). The Presentation of Self in Everyday Life. Harmondsworth: Pelican.

Goldberg, E., Garcia, A., R. and Manley, M.H. (2018). Monosexual and nonmonosexual women in same-sex couples' relationship quality during the first five years of parenthood. Sexual and Relationship Therapy, 33(1-2): 190212.

Gutmann Kahn, L., \& Lindstrom, L. (2015). “I just want to be myself”: Adolescents with disabilities who identify as a sexual or gender minority. The Educational Forum, 79(1): 362-376.

Hall, D.E. (1996). BI-introduction II: Epistemologies of the Fence. In D. E. Hall and M. Pramaggiore (Eds.) RePresenting Bisexuality: Subjects and Cultures of Fluid Desire (pp. 8-19). New York: New York University Press.

Hall, D.D. (1997). Lived Religion in America: Toward a History of Practice. Princeton: Princeton University Press.

Hartman, J.E. (2013). Creating a bisexual display: Making bisexuality visible. Journal of Bisexuality, 13(1): 39-62. 
Hartman-Linck, J.E. (2014). Keeping bisexuality alive: Maintaining bisexual visibility in monogamous relationships. Journal of Bisexuality, 14(2): 177-193.

Highleyman, L. (1995). Identity and Ideas: Strategies for Bisexuals. In N. Tucker (Ed.) Bisexual Politics: Theories, Queries and Visions (pp. 73-92). New York: Harrington Park Press.

House of Bishops. (2003). Some Issues in Human Sexuality: A Guide to the Debate. London: Church House Publishing.

Jeffreys, S. (1999). Bisexual politics: A superior form of feminism? Women's Studies International Forum, 2(3): 273-285.

Jenkins, R. (2014). Social Identity. London: Routledge.

Kim, J. (2015). The Four Types of Attraction. [online] Psychology Today. Available at: https://www.psychologytoday.com/gb/blog/valley-girl-brain/201504/thefour-types-attraction [Accessed 2 Aug. 2018].

Klesse, C. (2016). The Spectre of Promiscuity: Gay Male and Bisexual Nonmonogamies and Polyamories. London: Routledge.

Lanser, S.S. (2018). Queering narrative voice. Textual Practice, 2(6): 923-937.

Lawler, S. (2013). Identity: Sociological Perspectives. Cambridge: Polity Press.

Lord, E. (2016). What Does Demisexual Mean? Here Are 6 Signs That You May Identify As Demisexual. [Online] Available at: https://www.bustle.com/articles/155277-what-does-demisexual-mean-hereare-6-signs-that-you-may-identify-as-demisexual. [Accessed 2 August 2018]

Maliepaard, E. (2017). Bisexuality in the Netherlands: Connecting bisexual passing, communities, and identities. Journal of Bisexuality, 17(3): 325-348. 
Mattsson, T. (2014). Intersectionality as a useful tool: Anti-oppressive social work and critical reflection. Affilia, 29(1): 8-17.

Mccall, L. (2005). The complexity of intersectionality. Signs: Journal of Women in Culture and Society, 30(3): 1771-1800.

McGuire, M.B., 2008. Lived Religion: Faith and Practice in Everyday Life. Oxford: Oxford University Press.

Monro, S., \& Richardson, D. (2010). Intersectionality and Sexuality: The Case of Sexuality and Transgender Equalities Work in UK Local Government. In Y. Taylor, S. Hines, and M. Casey (Eds.), Theorizing Intersectionality and Sexuality (pp. 99-118). London: Palgrave Macmillan.

Orsi, R., 1997. Everyday Miracles: The Study of Lived Religion. In D. D. Hall (Ed.), Lived Religion in America: Toward a History of Practice (pp. 3-21). Princeton: Princeton University Press.

Pennington, S. (2009). Bisexuals 'doing gender' in romantic relationships. Journal of Bisexuality, 9(1): 33-69.

Rich, A. (1980). Compulsory heterosexuality and lesbian existence. Signs, 5(4): 631660.

Roberts, T.S., Horne, S.G. and Hoyt, W.T. (2015). Between a gay and a straight place: Bisexual individuals' experiences with monosexism. Journal of Bisexuality, 15(4): 554-569.

Robinson, M. (2015). Bisexual People. In A. Thatcher (Ed.), The Oxford Handbook of Theology, Sexuality, and Gender (pp. 640-656). Oxford: Oxford University Press.

Shepherd, C.A. (2018a). Attitudes to non-monogamy among bisexual Christians in the UK and USA. [ONLINE] Available at: 
https://discoversociety.org/2018/07/03/attitudes-to-non-monogamy-amongbisexual-christians-in-the-uk-and-usa/. [Accessed 9 August 2018]

Shepherd, C.A. (2018b). Bisexuality and the Western Christian Church: The Damage of Silence. London: Palgrave

Stone, S.D. (1996). Bisexual women and the 'threat' to lesbian space: Or what if all the lesbians leave? Frontiers: A Journal of Women Studies, 16(1): 101-116.

Storr, M. (1999). Postmodern bisexuality. Sexualities, 2(3): 309-325.

Thumma, S. (1991). Negotiating a religious identity: The case of the gay evangelical. Sociological Analysis, 52(4): 333-347.

Toft, A. (2009). Bisexual Christians: The Life-Stories of a Marginalised Community. In S. Hunt (Ed.) Contemporary Christianity and LGBT Sexualities (pp. 67-85). Farnham: Ashgate.

Toft, A. (2012). Bisexuality and Christianity: Negotiating Disparate Identities in Church Life. In S.J. Hunt and A.K.T. Yip (Eds.) The Ashgate Research Companion to Contemporary Religion and Sexuality (pp. 189-210).Farnham: Ashgate.

Toft, A. (2014). Re-imagining bisexuality and Christianity: The negotiation of Christianity in the lives of bisexual women and men. Sexualities, 17(5-6): 546564.

Toft, A. and Yip, A.K.T. (2018). Intimacy negotiated: The management of relationships and the construction of personal communities in the lives of bisexual women and men. Sexualities, 21(1-2): 233-250.

Walby, S., Armstrong, J. and Strid, S. (2012). Intersectionality: Multiple inequalities in social theory. Sociology, 46(2): 224-240. 
Wilcox, M.M. (2003). Coming Out in Christianity: Religion, Identity and Community. Bloomington: Indiana University Press.

Wilkinson, S. (1996). Bisexuality a la mode. Women's Studies International Forum, (19)3: $293-301$.

Woodhead, L. (2001). The Turn to Life in Contemporary Theology and Spirituality. In U. King (Ed.), Spirituality and Society in the New Millennium (pp. 110123). Brighton: Sussex Academic Press.

Yip, A.K.T. (2005). Queering religious texts: An exploration of British nonheterosexual Christians' and Muslims' strategy of constructing sexualityaffirming hermeneutics. Sociology, 39(1): 47-65. 